\title{
How many cancer deaths could New Zealand avoid if five-year relative survival ratios were the same as in Australia?
}

\author{
Peter Sandiford, ${ }^{1}$ Manar E. Abdel-Rahman, ${ }^{2}$ Claudia Allemani, ${ }^{3}$ Michel P. Coleman, ${ }^{3}$ Geeta Gala ${ }^{4}$
}

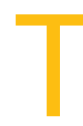

he New Zealand cancer registry was established in 1948, with compulsory registration of cancer cases dating from 1994. Population-based cancer registration makes it possible to monitor trends in survival for each type of cancer by age, gender and other factors including, in New Zealand (NZ), ethnicity. These trends are published regularly by the NZ Ministry of Health, the most recent covering the period 1994 to 2009 . $^{1}$

Robust and consistent systems of cancer registration also permit international comparisons of cancer survival. These comparisons can help countries to identify problems in their registration systems and to benchmark the performance of their health systems against similar countries. A comparison of cancer survival in Britain with that of the rest of Europe found that $6-7 \%$ of the excess deaths among cancer patients (the number of deaths in excess of the expected or background mortality) would have been avoidable if survival in Britain were as high as the mean for Europe, and $10.6 \%$ if it had been as good as that in the European countries with highest survival. ${ }^{2}$ Britain's poor performance in comparisons with other developed countries was a driver for the investment and policies set out in the 2011 national cancer strategy. ${ }^{3}$

Survival estimates for 1999-2007 from 107 cancer registries in 29 European countries collated through the EUROCARE project have been published. ${ }^{4}$ The first CONCORD study compared cancer survival for breast, colon, rectum and prostate from 101 registries in 31 countries on five continents. ${ }^{5}$ Australia

\begin{abstract}
Aim: To determine how many Māori and non-Māori deaths might have been avoidable if cancer survival in New Zealand were as high as in Australia.

Methods: Age-sex-tumour specific five-year relative survival ratios were calculated for cancer patients diagnosed with 27 tumour sites (representing about 92\% of all cancers) in 2006-10. These were used to estimate the number of Māori, non-Māori and total deaths (and proportion of excess deaths) that would have been avoidable within five years of diagnosis had New Zealand's relative survival been equivalent to Australia's.

Results: A total of 3,631 cancer deaths (726/year; $13.4 \%$ of excess deaths) could have been avoidable. Among 25 tumours where ethnic-specific results were estimated, there were 851 potentially avoidable deaths in Māori (24.9\%) and 2,758 in non-Māori (11.8\%). Breast, bowel, lung and prostate tumours made up $64 \%$ of avoidable deaths. Those with the highest proportions of avoidable deaths were thyroid (44.7\%), prostate (35.5\%), breast (30.0\%) and uterus (23.5\%). More than $50 \%$ of Māori melanoma, prostate, testis and thyroid cancer deaths were avoidable.

Conclusion: A significant number of cancer deaths could be avoidable if New Zealand achieved Australia's relative survival ratios. The proportion is much higher for Māori than for non-Māori. Implications: There is considerable scope to improve cancer outcomes in New Zealand. Key words: cancer, relative survival, New Zealand, avoidable mortality, Māori
\end{abstract}

participated, but not NZ. CONCORD-2 will extend these comparisons to 10 common cancers with data from more than 250 cancer registries in about 60 countries, including NZ. To our knowledge, no published studies have provided a direct and comprehensive comparison of cancer survival in NZ with that in Australia. Survival in Australia ranked in the top 10 in the CONCORD study for all four cancers examined and in both sexes, making it a high-performing comparator for NZ. We have compared cancer survival in $\mathrm{NZ}$ and Australia using a similar approach to Abdel-Rahman et al. ${ }^{2}$ to estimate the number and proportion of excess deaths that would have been avoidable among patients with each type of cancer in NZ if survival were equivalent to that in Australia.

Literature on the epidemiology of cancer survival has established the concepts of 'avoidable' and 'excess' cancer deaths used in this paper. ${ }^{2,-11}$ Formal definitions are provided in the methods section, but we emphasise that the term 'avoidable cancer deaths' is used in comparisons of two or more populations to indicate the numbers of individuals in the population(s) with lower relative survival (of cancer) who would have

\footnotetext{
1. Planning, Funding and Outcomes Division, Waitemata District Health Board, New Zealand

2. Department of Statistics, Faculty of Mathematical Sciences, University of Khartoum, Sudan

3. Cancer Research UK Cancer Survival Group, Department of Non-communicable Disease Epidemiology, London School of Hygiene and Tropical Medicine, UK

4. Northern Cancer Network, Northern Regional Alliance, New Zealand

Correspondence to: Mr Peter Sandiford, Planning, Funding and Outcomes Division, Waitemata District Health Board, 15 Shea Terrace, Auckland 0740, New Zealand;

e-mail: peter.sandiford@waitematadhb.govt.nz
}

Submitted: May 2014; Revision requested: May 2014; Accepted: October 2014

The authors have stated they have no conflict of interest.

Aust NZ J Public Health. 2015; 39:157-61; doi: 10.1111/1753-6405.12344 
survived, had relative survival been as high as in the population with the best relative survival ratio. The deaths are only truly avoidable if the population with the lower relative survival could potentially achieve the higher relative survival ratio. This issue is revisited in the discussion section.

Similarly, confusion may arise with the term 'excess' cancer deaths. In this case the 'excess' refers to deaths in patients diagnosed with cancer that are over and above those that would have been expected in the general population without cancer. Excess deaths can be thought of as the number of deaths in patients diagnosed with cancer that can be attributed to the cancer within the follow-up period (in this case five years).

The other term used extensively in this paper is 'relative survival'. It is widely used in cancer epidemiology and refers to the ratio of observed survival (e.g. in a group of cancer patients) to the survival of the general population..$^{12}$ Deaths in the general population are referred to as background mortality.

\section{Methods}

\section{Data sources}

Estimates of the five-year cumulative relative survival ratio by age and sex for each type of cancer for patients diagnosed Australia in 2006-10 were obtained from online tables published by the Australian Institute of Health and Welfare. ${ }^{13}$ These are derived from the Australian Cancer Database (ACD), which is compiled and maintained by AlHW in partnership with the Australasian Association of Cancer Registries. ${ }^{14}$ Each Australian state and territory has a separate registry, but these have a minimum data set that is submitted to the Australian Cancer Database: all states have legislation making the reporting of cancer mandatory. AlHW performs internal linking checks to identify patients who had tumours diagnosed in more than one state or territory, thus reducing duplication to a negligible level. Death records held in the National Death Index are routinely linked to the ACD. Additional detail on the Australian Cancer Database and National Death Index are provided in Appendix C of the report. ${ }^{14}$

The NZ cancer registry provided data for patients diagnosed between 2001 and 2007 and followed up to 31 December 2010. These data make it possible to apply the period approach to predict five-year relative survival for patients diagnosed in 2006-10 by using the survival experience of patients who were diagnosed in earlier years and who were alive at some point during 2006-10. The NZ registry performs a number of routine measures to maximise the quality of the data. Additional details on the content and quality of the data are provided on the Ministry of Health website (http://www.health.govt.nz).

Both the NZ and Australian registries used the tenth revision of the International Statistical Classification of Diseases and Related Health Problems (ICD-10) for coding the tumour site throughout the period covered by this study.

AlHW linked data on deaths from the Australian National Mortality Database to the Australian Cancer Database to estimate the survival time of each cancer patient. All-cause mortality rates from the Australian Bureau of Statistics were used to derive national life tables of background mortality in order to estimate expected survival.

Data on deaths in NZ are recorded in the National Mortality Collection, equivalent to the Australian National Mortality Database. Death records registered on or before 31 December 2010 were linked to the cancer registry by their encrypted National Health Index number to establish the survival time for each patient. Complete period life tables for 2000-02, 2005-07 and 2010-12 for Māori and non-Māori, produced by Statistics NZ, were interpolated using the fraction method described by Micheli et al. ${ }^{15}$ to produce life tables for each year from 2001 to 2010.

\section{Cancers studied}

We studied the same 27 malignancies for which AlHW has published survival estimates: these represented $91.8 \%$ of all cancers diagnosed in NZ during the period 20062010. The ICD-10 codes used to define each cancer type are shown in Table 1.

\section{Selection criteria}

The selection criteria used by AlHW were followed as closely as possible in selecting the NZ patients to be included in the analyses. The only difference in exclusion criteria between the Australian and NZ data was that NZ patients aged 100 or over were excluded from the analyses because the life tables available for 2006-07 did not extend beyond the age of 100 , making it difficult to estimate expected survival. The effect on survival estimates would be negligible, given that there were only 18 patients diagnosed at age 100 years or over in the NZ data $(0.1 \%$ of all those aged 80 and over). Table 2 shows the included and excluded population of the NZ and Australian groups.

\section{Survival and avoidable deaths}

Avoidable cancer deaths were calculated in the same manner as Abdel-Rahman et al. ${ }^{2}$ This method partitions the total deaths into those that are 'expected' given the background mortality rate in the population and 'excess' deaths attributable to the cancer. ${ }^{16}$ For each cancer, the number of excess deaths was calculated as:

Excess deaths $=\sum_{i j k}\left[N_{i j k} \times E_{i j k} \times\left(1-R_{i j k}\right)\right]$

where $N$ is the incident number of cases of cancer, $E$ is the expected survival, and $R$ is the five-year relative survival ratio in age group $i$, sex $j$ and ethnic group (Mäori or non-Māori) $k$.

Relative survival is the ratio of the observed cumulative probability of survival in patients with tumour who survive a given period (in this case five years) and the survival that would have been expected during that time if the patients were only subject to the background mortality in the general population group (obtained from life tables). Relative survival ratios using the period approach ${ }^{17}$ were available for Australia using the Ederer II method, ${ }^{12}$ as described in the Australian cancer survival report. ${ }^{14} \mathrm{We}$ followed the same methodology to calculate relative survival ratios for NZ. Unlike the cohort method, the period method gives more up-to-date estimates of cancer survival by making use of all survival information up to the final point of follow-up.

Data were obtained on all cancer patients diagnosed in NZ during 2001-07 and followed up until 31 December 2010. Relative survival ratios were calculated using the period approach to predict five-year relative survival in 2006-10 using the strs command in Stata. Relative survival was estimated separately for Māori and non-Māori.

Period estimates of the Australian five-year relative survival ratios for the same period (2006-10), again based on patients diagnosed from 2001 to 2007, were taken from the AlHW publication. Australian relative survival estimates were not published for age-sex strata with fewer than 20 individuals alive at the start of the follow-up year, and these strata were excluded from the avoidable mortality calculations.

'Avoidable' deaths are estimated as the number of excess deaths that would not have occurred if five-year relative survival in NZ in each age-sex group for each cancer had been equivalent to that in Australia for 2006-10: 
Excess deaths $=\sum_{i j k}\left[N_{i j k} \times E_{i j k} \times\left(1-R_{i j k}\right)\right]$

where $E_{i j k}$ is the expected survival in NZ in stratum ijk and is the number of incident tumours in NZ during 2006-2010. Avoidable deaths were calculated separately for Mäori and non-Mäori, for age and sex, and for each tumour type, using the Australian population as the sole comparato. Ethnic-specific numbers of avoidable deaths were not presented for the tumour groups in which there were fewer than 20 Mãori cases in the five-year period (lip, mesothelioma and unknown site). Avoidable deaths were calculated and presented for the five-year period 2006-2010 and also as annual numbers. In addition to presenting absolute numbers of avoidable deaths, we present them as percentages of excess deaths for each tumour type.

\section{Ethnicity}

Ethnicity was classified as Mãori or nonMāori in accordance with the available life tables. In NZ, ethnicity is based on selfdeclaration and multiple ethnicities are recorded..$^{18}$ To deal with multiple ethnicities, a subject with any ethnicity code of Māori was classified as Māori. The way ethnicity was assigned in the NZ Cancer Registry changed in 2009 with the introduction of

\begin{tabular}{|c|c|c|c|c|}
\hline \multirow[t]{2}{*}{ Criteria } & \multicolumn{2}{|c|}{ Australia $^{14}$} & \multicolumn{2}{|c|}{ New Zealand } \\
\hline & Number & $\%$ & Number & $\%$ \\
\hline Patients included in analyses & $1,929,154$ & 97.9 & 114,169 & 96.8 \\
\hline Patients excluded ${ }^{\mathrm{a}}$ & 42,031 & 2.1 & 3,670 & 3.1 \\
\hline Age at diagnosis not known ${ }^{b}$ & 189 & 0.0 & 0 & 0.0 \\
\hline Death certificate only & 30,868 & 1.6 & 3,012 & 2.6 \\
\hline Invalid age & 125 & 0.0 & 29 & 0.0 \\
\hline Invalid sequence of death and diagnosis dates ${ }^{b}$ & 27 & 0.0 & 0 & 0.0 \\
\hline Zero survival time ${ }^{c}$ & 31,153 & 1.6 & 1,903 & 1.6 \\
\hline Multiple primary, same side and site ${ }^{d}$ & - & - & 56 & 0.0 \\
\hline Total cases diagnosede & $1,971,185$ & 100.0 & 117,895 & 100.0 \\
\hline \multicolumn{5}{|l|}{ a: Some patients met more than one criterion for exclusion. } \\
\hline \multicolumn{5}{|c|}{$b$ : These may have already been excluded from the New Zealand cancer registry data. } \\
\hline \multicolumn{5}{|c|}{$\begin{array}{l}\text { c: These exclusions are standard practice in survival analysis of cancer registry data and since they constitute just a small percentage of the total records their } \\
\text { exclusion is unlikely to significantly change the overall results. }\end{array}$} \\
\hline \multicolumn{5}{|c|}{ d: Other multiple primaries were included as recommended by Rosso et al32. } \\
\hline \multicolumn{5}{|c|}{$\begin{array}{l}\text { e: For Australia the period is 1982-2007, for New Zealand the period is 2001-2007. Patients not domiciled in the country have already been excluded, as have } \\
\text { secondary tumours, non-malignant tumours and recurrences from an already registered primary site. }\end{array}$} \\
\hline
\end{tabular}

Table 1: Total number of excess deaths and number of deaths that would be avoidable in New Zealand within 5 years of diagnosis, if survival were the same as in Australia: selected cancers, adults (15-99 years), Māori and non-Māori, diagnosed during 2006-2010.

\begin{tabular}{|c|c|c|c|c|c|c|c|c|c|c|c|}
\hline \multirow{3}{*}{ Site/type } & \multirow{3}{*}{$\begin{array}{l}\text { ICD } 10 \\
\text { Codes }\end{array}$} & \multirow{3}{*}{$\begin{array}{l}\text { Total malignant } \\
\text { cancers 2006-10 }\end{array}$} & \multicolumn{3}{|c|}{ Excess deaths } & \multicolumn{6}{|c|}{ Avoidable deaths } \\
\hline & & & \multirow[t]{2}{*}{ Māori } & \multirow[t]{2}{*}{ non-Māori } & \multirow[t]{2}{*}{ Total } & \multicolumn{2}{|c|}{ Māori } & \multicolumn{2}{|c|}{ non-Māori } & \multicolumn{2}{|c|}{ Total } \\
\hline & & & & & & No. & $\%$ of excess ${ }^{a}$ & No. & $\%$ of excess & No. & $\%$ of excess \\
\hline AML & See note b & 859 & 53 & 478 & 531 & 2 & 2.9 & 3 & 0.6 & 4 & 0.8 \\
\hline Bladder & C67 & 1,726 & 37 & 549 & 586 & 13 & 34.3 & 22 & 4.0 & 35 & 5.9 \\
\hline Bowel & $\mathrm{C} 18-\mathrm{C} 20$ & 13,677 & 295 & 4,073 & 4,368 & 117 & 39.6 & 483 & 11.9 & 600 & 13.7 \\
\hline Brain & $\mathrm{C} 71$ & 1,317 & 69 & 813 & 882 & 11 & 15.6 & 39 & 4.8 & 50 & 5.7 \\
\hline Breast & $\mathrm{C} 50$ & 13,368 & 269 & 1,494 & 1,763 & 134 & 49.8 & 395 & 26.4 & 529 & 30.0 \\
\hline Cervix & $\mathrm{C} 53$ & 806 & 46 & 149 & 195 & 11 & 23.4 & -13 & - & -2 & - \\
\hline CLL & C91.1 & 1,001 & 18 & 165 & 183 & 5 & 28.6 & -31 & - & -26 & - \\
\hline Gall bladder & $\mathrm{C} 23-\mathrm{C} 24$ & 494 & 43 & 297 & 340 & 6 & 13.5 & 18 & 6.0 & 23 & 6.9 \\
\hline Hodgkin & C81 & 477 & 1 & 61 & 62 & -1 & - & 14 & 22.9 & 13 & 20.5 \\
\hline Kidney & C64 & 2,146 & 68 & 540 & 608 & 30 & 43.4 & 77 & 14.3 & 107 & 17.5 \\
\hline Larynx & $\mathrm{C} 32$ & 422 & 19 & 125 & 145 & 4 & 21.8 & 16 & 12.6 & 20 & 13.8 \\
\hline $\operatorname{Lip}^{c}$ & $\mathrm{COO}$ & 225 & - & - & 25 & - & - & - & - & 11 & 43.8 \\
\hline Liver & $\mathrm{C} 22$ & 1,082 & 178 & 604 & 782 & 21 & 12.0 & 37 & 6.2 & 59 & 7.5 \\
\hline Lung & C33-C34 & 8,685 & 1,338 & 5,489 & 6,827 & 208 & 15.6 & 488 & 8.9 & 697 & 10.2 \\
\hline Melanoma & C43 & 13,513 & 35 & 1,280 & 1,315 & 24 & 68.7 & 257 & 20.1 & 281 & 21.4 \\
\hline Mesothelioma ${ }^{c}$ & $C 45$ & 435 & - & - & 344 & - & - & - & - & 10 & 3.0 \\
\hline Myeloma & C90 & 1,344 & 69 & 575 & 645 & 23 & 33.8 & 18 & 3.1 & 41 & 6.4 \\
\hline Non-Hodgkins & C82-C85 & 3,604 & 86 & 992 & 1,078 & 39 & 44.7 & 187 & 18.8 & 225 & 20.9 \\
\hline Oesophagus & $\mathrm{C} 15$ & 1,343 & 83 & 910 & 993 & 14 & 16.3 & 85 & 9.4 & 99 & 10 \\
\hline Ovary & $\mathrm{C} 56$ & 1,365 & 89 & 667 & 756 & 25 & 28.5 & 67 & 10 & 92 & 12.2 \\
\hline Pancreas & $\mathrm{C} 25$ & 1,970 & 168 & 1,389 & 1,557 & 8 & 4.5 & 58 & 4.2 & 66 & 4.2 \\
\hline Prostate & C61 & 14,493 & 124 & 1,202 & 1,325 & 89 & 71.9 & 382 & 31.8 & 471 & 35.5 \\
\hline Stomach & $\mathrm{C} 16$ & 1,772 & 246 & 899 & 1,144 & 42 & 17.2 & 58 & 6.5 & 101 & 8.8 \\
\hline Testis & C62 & 784 & 9 & 11 & 19 & 5 & 52.9 & -5 & - & 0 & - \\
\hline Thyroid & $\mathrm{C} 73$ & 1,157 & 12 & 65 & 77 & 7 & 62.4 & 27 & 41.6 & 35 & 44.7 \\
\hline Uterus & C54-C55 & 2,100 & 46 & 361 & 408 & 12 & 26.5 & 84 & 23.1 & 96 & 23.5 \\
\hline TOTAL & & 90,655 & 3,417 & 23,333 & 27,119 & 851 & 24.9 & 2,758 & 11.8 & 3,631 & 13.4 \\
\hline \multicolumn{12}{|c|}{ a: These are calculated from unrounded estimates and therefore may differ from those calculated from the numbers presented in the table. } \\
\hline \multicolumn{12}{|c|}{ b: ICD codes C92.0, C92.3-C92.5, C93.0, C94.0, C94.2, C94.4, C94.5 } \\
\hline \multicolumn{12}{|c|}{ c: Numbers were too small to produce ethnic specific estimates for these tumours. } \\
\hline Abbreviations: AML & myeloid leukaer & $C L L=$ Chronic lymphoc & & & & & & & & & \\
\hline
\end{tabular}


an ethnicity algorithm to reduce previously documented undercounting of Māori Pacific and Asian events. ${ }^{19,20}$ This algorithm was run retrospectively across all registrations back to 1989 and so applied to all of the data used in this analysis. This algorithm searches the National Health Index, the Mortality Collection and National Minimum Dataset for ethnicity information. The ethnicity recorded in the cancer registry dataset was taken as definitive.

Māori and non-Māori life tables rely on census and mortality collection data for ethnicity classification. Record-linkage studies have found reasonably good agreement between the two sources. ${ }^{21}$ Clearly, cancer survival analysis relies on multiple sources of ethnicity measurement of varying quality and accuracy, with census data regarded as the gold standard. A recent study suggests that the quality of hospital ethnicity data (widely used in the cancer registry), has improved over time and is now quite high. ${ }^{22}$

\section{Results}

A total of $90,655 \mathrm{NZ}$ patients with one of the 27 types selected for study were diagnosed between 1 January 2006 and 31 December 2010 (Table 1), among whom 27,119 deaths in excess of the number expected from background mortality were recorded. Relative cancer survival was generally lower in NZ than in Australia, and some excess deaths would have been avoidable for 23 of the 27 cancers if survival had been the same in NZ as in Australia (24 of 25 for Māori and 21 of 25 for non-Māori).

For cancers with lower five-year survival in NZ than in Australia, 3,663 deaths would have been avoidable if NZ had experienced the same relative survival as Australia (13.5\% of excess deaths). For cancers with higher survival in NZ than Australia, only 33 deaths were avoided in NZ ( $0.1 \%$ of excess deaths), Table 1. The net effect of these differences in five-year relative survival between Australia and NZ was 3,631 avoidable deaths among cancer patients diagnosed in NZ over the five-years 2006-10, or 726 deaths per year (13.4\% of the excess deaths). It was found that a flat increase of $4.6 \%$ in NZ survival across all tumour groups would be needed to reduce the number of avoidable deaths to zero.

Mãori made up 851 of the avoidable deaths (170 per year), representing $24.9 \%$ of all excess deaths among Māori. Avoidable deaths comprised more than $50 \%$ of the excess deaths among Māori for melanoma, prostate, testis and thyroid.

Among non-Māori, the 2,758 avoidable deaths (552 per year) represented $11.8 \%$ of the excess deaths. The highest proportion was for thyroid cancer (41.6\%). More than $20 \%$ of excess deaths would have been avoidable for six of the 25 cancers for which survival was lower in NZ (thyroid, breast, Hodgkin, prostate, uterus and melanoma), and more than $10 \%$ for a further five tumour sites (non-Hodgkin lymphoma, kidney, larynx, bowel and ovary).

The proportion of avoidable deaths was almost always higher for Mãori than nonMāori. The only malignancy for which the proportion of avoidable deaths was lower in Māori than non-Māori was Hodgkin lymphoma, the least common of the malignancies for which separate estimates could be made for each ethnicity.

The proportionate distribution of avoidable deaths in Mãori and non-Māori cancer patients is shown in Figure 1. Seven of the 25 malignancies with avoidable excess deaths in NZ accounted for $77 \%$ of all the avoidable deaths in Māori and 82\% in non-Māori, but their relative importance varied somewhat, with stomach and lung making up higher proportions in Mãori and melanoma accounting for a higher proportion in nonMāori. Cancers with the highest proportions of avoidable excess deaths for Māori and non-Māori were thyroid (39.2.0\%), lip (31.7\%), breast $(26.1 \%)$ and prostate $(25.8 \%)$.

\section{Discussion}

The application of health needs analysis to public health practice, resource allocation, prioritisation and service performance appraisal is often frustrated by the difficulty of determining how much of a given health burden is truly avoidable. Benchmarking against a high-performing comparator is one way to achieve this aim. Australia's high cancer survival compared with other (mainly
European) countries in the CONCORD study ${ }^{5}$ suggests that it may be as good as 'the best of Europe'.

Australia is a significantly wealthier country than NZ, with higher levels of per person health expenditure (US $\$ 3,800$ versus US $\$ 3,042$ in 2010), ${ }^{23}$ and slightly higher life expectancy. ${ }^{24}$ Total health expenditure is a relatively crude metric of health system investment in the management of cancer, but it is correlated with survival, ${ }^{25,26}$ and so it is not surprising that survival in Australia is higher than in NZ. The results are consistent with those from the CONCORD study, where poorer countries tended to have lower cancer survival ratios, ${ }^{5}$ and survival among blacks in the US was lower than among whites.

The estimates of avoidable deaths are derived from differences in five-year survival after taking into account the differences in background mortality by age, sex and over time between countries, and, in NZ, between Māori and non-Māori. The avoidable deaths in NZ may reflect a combination of earlier diagnosis, faster access to treatment and more effective therapy in Australia.

Previous international comparisons of cancer survival have been criticised on the grounds that differences in the quality of registration systems may account for some of the estimated differences in survival. ${ }^{27}$ Survival in NZ could appear lower than in Australia if the follow-up of cancer patients were more complete in NZ than Australia. This is unlikely: both countries have compulsory cancer registration and national mortality databases of high quality and completeness. Further, the survival estimates for NZ were derived with specific life tables for each sex and ethnicity, while the Australian estimates were derived with a single set of life tables for each sex, so the estimates of avoidable deaths are more likely to be conservative. This is because some Māori deaths that would have been attributed to cancer (as excess deaths) with national life tables are taken (correctly) as background mortality and hence the
Figure 1: Distribution of avoidable deaths by tumour site and ethnicity.

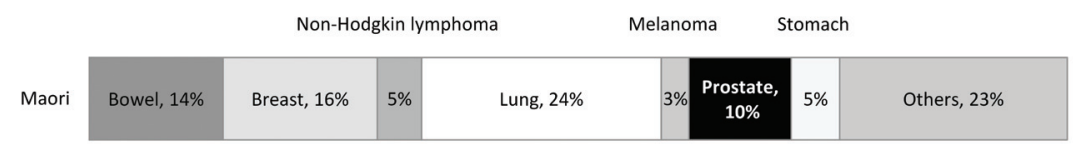

Non-Hodgkin lymphoma Melanoma Stomach, $2 \%$

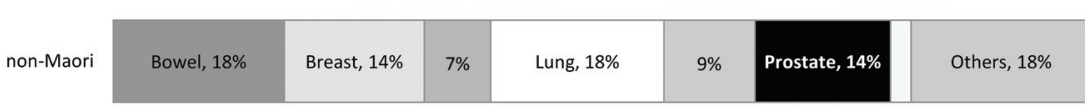


relative survival in that group increases. If separate life tables had been used for Pacific ethnicity patients then the non-Māori relative survival estimates would have been slightly higher, but there would still have been a survival deficit between NZ and Australia. Using separate life tables for Aboriginal and Torres Strait Island Australians (2.3\% of the population in the 2011 census) would have had only a very small effect on the avoidable mortality estimates.

For certain sites, lead-time bias and overdiagnosis may explain some of the observed survival differences. For example, variation in the use of prostate-specific antigen, and in the intensity of investigation following an abnormal result, could lead to a higher proportion of relatively indolent prostate tumours. It is not known whether Australia differs from NZ in this respect, but it is noteworthy that the age-standardised incidence rate of prostate cancer during 2003-07 was higher in Australia than in NZ (120.0 versus 102.6 per 100,000). ${ }^{28,29}$ Prostate cancer comprised $25.7 \%$ of the total avoidable excess deaths among men. Excluding prostate cancer reduces the total number of avoidable deaths to 3,193 , which is $12.4 \%$ of non-prostate excess mortality.

Similarly, more complete or more thorough breast screening (e.g. through earlier introduction of digital mammography) might also introduce lead-time bias, length bias or over-diagnosis, which could affect survival. One might expect this to produce higher incidence rates but incidence rates in Australia and NZ during 2003-07 were almost identical (89.3 versus 90.6 ). It is less likely that such biases could explain the large differences in survival for non-Hodgkin lymphoma, where incidence rates in Australia and NZ were also similar (13.9 and 14.8). ${ }^{28,29}$

These findings once again draw attention to the unacceptable ethnic disparities in cancer survival in NZ, which have been noted by others, ${ }^{30}$ but they also demonstrate that the problem is not simply one of ethnic disparities. The absolute numbers of avoidable deaths were higher for non-Māori than Māori. In other words, the survival disparities with Australia are far higher for Māori, with more than $50 \%$ of avoidable excess deaths for several cancers, but the number of avoidable excess deaths is higher among non-Maori, because they represent a higher proportion of all cancer patients. It was not possible from this work to examine the ethnic inequalities in Australian cancer survival, but it should be noted that these are also unacceptably large. ${ }^{31}$

The proportion of all excess deaths that are potentially avoidable in this study of 27 tumour types comprising about $92 \%$ of all cancers gives an indication of the scope for improvement in survival in NZ. Although we calculated that five-year relative survival in NZ would have to have been $4.6 \%$ higher for all tumour sites to eliminate the avoidable mortality compared Australia, the disparities in survival are not evenly distributed, and so there is greater scope for improvement with some tumour types than others (e.g. prostate, thyroid, breast and lip).

For 20 of the 27 malignancies we studied, at least $5 \%$ of the excess deaths among NZ cancer patients were potentially avoidable. These sites are heterogeneous in terms of organ system, treatment modality and the existence of a national screening program. This suggests that the causes of the survival disparities with Australia may be general rather than tumour-specific. However, it may require careful and detailed comparative research into those specific tumour sites with the largest proportions of avoidable deaths in order to elucidate these underlying reasons for the survival differences.

\section{References}

1. Ministry of Health. Cancer Patient Survival Change Over Time Update: Covering the Period 1994 to 2009. Wellington (NZ): Government of New Zealand; 2012.

2. Abdel-Rahman M, Stockton D, Rachet B, Hakulinen T, Coleman M. What if cancer survival in Britain were the same as in Europe: How many deaths are avoidable? Br J Cancer. 2009;101:S115-S24.

3. Department of Health.Improving Outcomes:AStrategy for Cancer. London (UK): Government of United Kingdom; 2011.

4. De Angelis R, Sant M, Coleman MP, Francisci S, Baili P, Pierannunzio D, et al. Cancer survival in Europe 19992007 by country and age: Results of EUROCARE-5-a population-based study. Lancet Oncol. 2014;15(1): 23-34.

5. Coleman MP, Quaresma M, Berrino F, Lutz J-M, De Angelis R, Capocaccia R, et al. Cancer survival in five continents: A worldwide population-based study (CONCORD). Lancet Oncol. 2008;9(8):730-56.

6. Seppä K, Hakulinen T, Läärä E. Avoidable deaths and random variation in patients' survival. Br J Cancer. 2012;106(11):1846-9.

7. Lambert PC, Holmberg L, Sandin F, Bray F, Linklater KM, Purushotham A, etal. Quantifying differences in breast cancer survival between England and Norway. Cancer Epidemiol. 2011;35(6):526-33.

8. Møller H, Sandin F, Bray F, Klint Å, Linklater KM, Purushotham A, et al. Breast cancer survival in England, Norway and Sweden:A population-based comparison. Int J Cancer. 2010;127(11):2630-8.

9. Holmberg L, Robinson D, Sandin F, Bray F, Linklater K, Klint $\AA$, et al. A comparison of prostate cancer survival in England, Norway and Sweden: A population-based study. Cancer Epidemiol. 2012;36(1):e7-e12.

10. Dickman PW, Gibberd RW, Hakulinen T. Estimating potential savings in cancer deaths by eliminating regional and social class variation in cancer survival in the Nordic countries. J Epidemiol Community Health. 1997;51(3):289-98.
11. Pokhrel A, Martikainen P, Pukkala E, Rautalahti M, Seppä K, Hakulinen T. Education, survival and avoidable deaths in cancer patients in Finland. $\mathrm{Br} J$ Cancer. 2010;103(7):1109-14.

12. Ederer $\mathrm{F}$, Heise $\mathrm{H}$. Instructions to IBM 650 Programmers in Processing Survival Computations. Bethesda (MD): National Cancer Institute; 1959.

13. Australian Institute of Health and Welfare. Cancer Survival and Prevalence in Australia: Period Estimates from 1982 to 2010: Additional Material - Supplementary Tables [Internet]. Canberra (AUST): AlHW; 2012 [cited 2013 Sep 18]. Available from: http://www.aihw.gov. au/publication-detail/?id $=10737422720 \&$ tab $=3$

14. Australian Institute of Health and Welfare. Cancer Survival and Prevalence in Australia: Period Estimates from 1982 to 2010. Cancer Series No.: 69. Canberra (AUST): AlHW; 2012.

15. Micheli A, Baili P, Quinn M, Mugno E, Capocaccia R, Grosclaude P. Life expectancy and cancer survival in the EUROCARE-3 cancer registry areas. Ann Oncol.2003;14 Suppl 5:v28-40.

16. Estève J, Benhamou E, Croasdale M, Raymond L. Relative survival and the estimation of net survival: elements for further discussion. Stat Med. 1990;9(5): 529-38.

17. Brenner $H$, Gefeller O. An alternative approach to monitoring cancer patient survival. Cancer. 1996;78(9):2004-10.

18. Ministry of Health. Ethnicity Data Protocols for the Health and Disability Sector. Wellington (NZ): Government of New Zealand; 2004

19. Brazier J, Roberts J, Deverill M. The estimation of a preference-based measure of health from the SF-36.J Health Econ. 2002;21(2):271-92.

20. Shaw C, Atkinson J, Blakely T. (Mis)classification of ethnicity on the New Zealand Cancer Registry: 19812004. NZMed J. 2009;122(1294):10-22.

21. Tan L, Blakely T, Atkinson J. Ethnic counts on mortality and census data 2001-06: New Zealand censusmortality study update. N Z Med J. 2013;123(1320): 37-44.

22. Rumball-Smith J,Sarfati D. Improvement in the accuracy of hospital ethnicity data. N Z Med J. 2011;124(1340): 96-7.

23. Organisation for Economic Co-operation and Development. Total Expenditure on Health Per Capita. Health:Key Tables from OECD [Internet].Paris (FRA):OECD; 2013 [cited 2013 Oct 14]. Available from: http://www. oecd-ilibrary.org/social-issues-migration-health/totalexpenditure-on-health-per-capita_20758480-table2

24. Van Oeffelen L, Vaartjes I, Stronks K, Bots M, Agyemang C. Abstract P171: Ethnic inequalities in cardiac revascularization after acute coronary syndrome. Circulation. 2014;129 Suppl 1:AP171.

25. Organisation for Economic Co-operation and Development. CancerCare: Assuring Quality to Improve Survival. OECD Health Policy Studies. Paris (FRA): OECD Publishing; 2013.

26. Kressin NR, Petersen LA. Racial Differences in the Use of Invasive Cardiovascular Procedures: Review of the Literature and Prescription for Future Research. Ann Intern Med. 2001;135(5):352-66.

27. Autier P, Boniol M. Caution needed for country-specific cancer survival. Lancet. 2011;377(9760):99-101.

28. Ministry of Health. Cancer:New Registrations and Deaths 2010. Wellington (NZ): Government of New Zealand; 2013.

29. Australian Institute of Health and Welfare. ACIM (Australian Cancer Incidence and Mortality) Books. Canberra (AUST): AlHW; 2012.

30. Jeffreys $M$, Stevanovic V, Tobias M, Lewis C, EllisonLoschmann L, Pearce N, et al. Ethnic inequalities in cancer survival in New Zealand: Linkage study. Am J Public Health. 2005;95(5):834-7.

31. Drummond M, Schulpher M, Torrance G, O'Brien B, Stoddart G. Methods for the Economic Evaluation of Health Care Programmes. Oxford (UK): Oxford University Press; 2005.

32. Rosso S, De Angelis R, Ciccolallo L, Carrani E, Soerjomataram I, Grande E, et al. Multiple tumours in survival estimates. Eur J Cancer. 2009;45(6):1080-94. 